\title{
Comparison of Socioeconomic Characteristics between Childless and Procreative Couples after Implementation of the Two-Child Policy in Inner Mongolia, China
}

\author{
Xinhua Li, Ph.D. ${ }^{1,2}$, Yancun Fan, Ph.D. ${ }^{1}$, Sawitri Assanangkornchai, M.D., Ph.D. ${ }^{2}$, \\ Edward Braddon McNeil, M.Sc. ${ }^{2}$
}

${ }^{1}$ Faculty of Health Management, Inner Mongolia Medical University, Jin Shan Development Zone, Hohhot 010020, China.

${ }^{2}$ Epidemiology Unit, Faculty of Medicine, Prince of Songkla University, Hat Yai, Songkhla 90110, Thailand.

Received 14 November 2019 • Revised 23 April 2020 • Accepted 25 April 2020 • Published online 22 June 2020

\begin{abstract}
:
Objective: In the context of China's "two-child" policy, this study aims to compare socio-demographic characteristics and attitudes towards the desired number of children among couples of different family size. We describe the major reasons for and against couples raising a (further) child based on the theory of planned behavior.
\end{abstract}

Material and Methods: An interview-based survey was conducted in Inner Mongolia among couples visiting marital registration offices, antenatal care clinics, kindergartens, and primary schools. Using prevalence ratios and $95 \%$ confidence intervals estimated from multivariate log-binomial regression models, socio-demographic characteristics and attitudes towards the two-child policy were compared between three types of couples: those without children, those with one child, and those with multiple children.

Results: The sample consisted of 2,013 women aged 20-49 years and their partners. The top difficulty in raising a child was "increased economic burden". Factors significantly associated with a reduced prevalence of raising children included the woman's marital age and the couple's educational achievement, employment status, and monthly income. Factors associated with an increased prevalence of raising children included a lack of inter-couple communication, having a perception of the strong influence of the two-child policy, and Han ethnicity.

Contact: Prof. Sawitri Assanangkornchai, M.D., Ph.D.

Epidemiology Unit, Faculty of Medicine, Prince of Songkla University,

Hat Yai, Songkhla 90110, Thailand.

E-mail: savitree.a@psu.ac.th

(c) 2020 JHSMR. Hosting by Prince of Songkla University. All rights reserved.

This is an open access article under the CC BY-NC-ND license

(http://www.jhsmr.org/index.php/jhsmr/about/editorialPolicies\#openAccessPolicy).
J Health Sci Med Res 2020;38(4):285-295 doi: 10.31584 /jhsmr.2020748 www.jhsmr.org 
Conclusion: Significant socio-demographic differences were seen between couples with and without children in China. Childless couples were more affluent than single- or multi-child couples and they perceived the two-child policy to be less influential on their decision to raise children.

Keywords: couples, socioeconomic characteristics, theory of planned behavior, two-child policy

\section{Introduction}

Childbearing is not a one-time decision, but a continuous decision making process, influenced by the social environment, individual characteristics, and the number of existing children in the family. ${ }^{1}$ In addition, the decision to conceive the first child has very different connotations compared to the transition to conceive two or more. ${ }^{2}$

China's one child policy was implemented in the 1970s and has made an important contribution to controlling the population. Following the policy, China now has the highest sex ratio (defined as the number of males per 100 females) in the world and has transitioned into an ageing society. ${ }^{3}$ In January 2016, after relaxation of the controversial one child policy, the Chinese government launched the universal two-child policy to counteract demographic changes in the population, skewed sex ratio, and decreasing labor force. ${ }^{4}$ Apart from China, most of the low fertility rate countries in $\mathrm{Asia}^{5}$ such as South Korea $^{6}$, Japan $^{7}$ and Singapore ${ }^{8}$ currently have a supportive population policy.

Due to the inadequate social welfare system for child care, many women of childbearing age and their partners worry about the difficulties in finding a suitable babysitter. A lack of quality education resources also contributes to their anxiety surrounding their child's education. For these reasons, the decision to have a second child is a difficult one to make for most couples. An analysis of online public posting in response to the two-child policy suggested that the huge surge in the population may not happen as quickly as expected. ${ }^{9}$
Within the family, couple's socioeconomic factors, their needs and attitudes as well as the discrepancies, may be the main driving force for most Chinese couples on their decision to have or not to have a (further) child. ${ }^{10}$ The controversy mainly surrounds females, where education attainment has been identified as the major factor influencing women's postponement of childbearing. ${ }^{11}$ However, studies from developed countries have failed to show any association between fertility rate and education level. ${ }^{12,13}$ Conflicting results between studies from Guangdong and Jiangsu provinces and those from Shaanxi and Hong Kong have also been found in China. ${ }^{2,14-16}$ Furthermore, no consensus has been reached concerning the influence of male socioeconomic status on childbearing. ${ }^{17}$ A couple usually operates as a decision-making unit about family size; however, no study has examined the association between couple's socioeconomic characteristics and fertility outcome.

Although Inner Mongolia was the first autonomous region in China to relax the one-child policy for Mongolian and other minority groups, the birth rate of Inner Mongolia has remained very low for many years. The aging process (defined as years spent in changing the population age structure from an adult structure to an older one) took only 17 years, which was one year earlier than the rest of the country. ${ }^{18,19}$ In 2015, the birth rate in Inner Mongolia was $7.7 \%$; markedly lower than the national birth $(12.1 \%){ }^{20}$ Evidence-based research that can advance the understanding of couple's socioeconomic characteristics and its association with family size in regions with a low fertility rate is urgently needed. 
The theory of planned behavior (TPB) is a validated psychosocial theory useful for understanding people's fertility decision and has been found to be effective in predicting a range of health intentions and behaviors, including dietary behaviors, physical activity, public relations, condom use, drug use, and health screening behavior. ${ }^{21}$ The theory states that intention toward attitude, and perceived behavior control, together shape an individual's behavior intention and behaviors.

In this study we aimed to compare socio-demographic characteristics, inter-couple communication, and perceptions of the influence of the universal two-child policy on the desired number of children to have among childless couples, those with one child, and those with more than one child. We also describe the major reasons for and against having a (further) child using a framework derived from the TPB.

\section{Material and Methods}

This was a facility-based, cross-sectional study, conducted in one urban city - Xin Cheng in Hohhot district, and one rural county - Zhuo Zi in Ulanqab district of Inner Mongolia province, China from April to June 2018. The study settings included marital register offices, antenatal care clinics, and kindergartens and primary schools. These settings were purposively chosen to ensure that we recruited enough couples in each outcome group.

Based on a previous study in 2016 , the proportion of eligible couples applying for permission to have a second child in China was $0.16 .^{22}$ To estimate this proportion with a precision of $5.0 \%$, and allowing for a $20.0 \%$ nonresponse rate and a design effect of 2 for cluster sampling, the sample size of this study was estimated to be 2,070 . To allow comparison of socioeconomic factors between types of couples when the proportion of a socio-economic factor of interest in one group was assumed to be at least 0.2 (as it was not known before) and a difference with the other group not more than 0.1 , with a confidence level of $95.0 \%$ and a power of $80.0 \%$, we needed at least 313 subjects per group. As the proportion of each type of couple in the whole sample was not known beforehand, we recruited as many couples per group as possible while maintaining the minimum sample size of 2,000. In each county, childless couples were recruited from marriage registration offices while couples with one or more children were recruited from antenatal clinics, kindergartens and primary schools. Data collection was conducted among couples in which the woman was of childbearing age (between 20-49 years).

The questionnaire was developed by conducting a literature review of studies related to fertility decision and the TPB, and in-depth interviews with ten participants. From the in-depth interviews, findings on the main reasons for a couple's decision to have another child and the conditions to be improved that would affect the second-child birth rate emerged. All questions centered around three dimensions of the TPB: social norms towards childbirth, attitudes towards having a child, and perceived behavior control on childbirth.

The validity of the questionnaire was assessed by a panel of experts, including one health policy researcher and three epidemiologists. A pilot study was conducted before the survey to ensure feasibility of the study and to test the questionnaire, which was modified after the pilot study and finalized by the team of experts.

The following 10 items describing the reasons for (6 items) and against (items 7-10) having a (further) child characterized the three aforementioned behavior dimensions: "attitudes towards the behavior" (items 3, 6, 9), "subjective norms" (items 1, 2, 4, 5) and "perceived behavior control" (items 7, 8, 10). 
1. A child is a bond of a couple.

2. A child fosters a good marital relationship.

3. I like children.

4. Two children can keep each other company.

5. Children are the hope of the family.

6. I enjoy having fun with a child.

7. Raising a (further) child increases the economic burden.

8. I have no time to raise a child.

9. Raising a child can negatively affect the chances of promotion in the work place.

10. It is difficult to raise a (further) child in modern society.

The dependent variable was the number of children in the couple's family, which was measured by the question: "How many children do you have?" with one of the three possible choices: "none", "one" or "more than one". Couples were then asked to provide at least three reasons influencing their decision to have a (further) child and at most three expected or existing difficulties or barriers in raising, or preventing them from raising, a child.

The independent variables included socioeconomic characteristics, inter-couple communication concerning the desired number of children to raise, and attitude towards the universal two-child policy in relation to the number of children they were allowed to have. Socioeconomic characteristics included wife's age at marriage, ethnicity (both Han or at least one minority), couple's education attainment (low: both senior high school or below, high: at least one with a college degree or above), combined monthly income (below 3,000, 3,0016,000 , more than 6,000 yuan), and employment status (both self-employed, at least one employed). Inter-couple communication concerning the number of children desired was measured by the question: "Have you and your spouse reached an agreement about the number of children you would like to raise/have in your family?", with responses being "Yes, we have reached an agreement", “No, we disagree' or 'We haven't discussed about this yet". The couple's attitude towards the universal two-child policy was measured by the question: "Do you think the two-child policy has affected your decision about the number of children you will have?" with responses being: "No" or "Yes".

Data collection was conducted by interviewers trained by the research team. Potential participants were identified by visiting marital registration offices, antenatal care clinics, and kindergartens and primary schools. The questionnaires were completed using face-to-face interviews. Of 2,221 individuals/couples approached, 2,018 (90.6\%) agreed to participate and be interviewed. The main reason for refusal among those who refused to participate was time constraints. Among the 2,018 study participants, five were excluded because of incomplete information. Finally, 2,013 couples were included in the analysis. Those who refused or had incomplete information were distributed approximately equally among the three outcome groups. The non-participants were also similar to the participating subjects in terms of sex, age group and ethnicity.

The data were entered into EpiData 3.1 and analyzed using $R$. Frequencies and percentages were used to describe the characteristics of participants. Chisquared and Kruskal-Wallis tests were performed to compare the differences in socio-economic factors among the three outcome groups. Multivariate log-binomial regression models were fit and adjusted prevalence ratios $(P R)$ and their $95 \%$ confidence intervals $(\mathrm{Cl})$ were computed using the childless couples as the baseline outcome group in the comparisons with single-child and with multi-child couples, respectively. Statistical significance was set at 0.05 .

Ethical approval and consent to participate:

Before collecting the data, written informed consent was 
obtained from all participants. The study protocol was approved by the Research Ethics Committee of the Faculty Medicine, Prince of Songkla University (reference number: 60-429-18-1). No additional ethnical approval was required from the four study sites.

\section{Results}

\section{Characteristics of couples}

Of the 2,013 study couples, 700 (34.8\%) had no children, $842(41.8 \%)$ had one child, and 471 (23.4\%) had more than one child. Table 1 compares socioeconomic characteristics between the three groups. The majority of the couples $(79.0 \%)$ belonged to the Han ethnicity with a higher proportion being found among couples who had multiple children. Multi-child couples were, in general, less educated than the other two groups with only $19.0 \%$ having a tertiary level of education. Multi-child couples also had a higher tendency to be self-employed and have a combined monthly income of less than 3,000 yuan. The women in this group also had a lower age at marriage.

Table 2 shows the inter-couple communication concerning the desired number of children and attitudes towards the two-child policy. In all three groups, more than $70.0 \%$ of the couples reached an agreement about the desired number of children to raise. However, significantly fewer couples in the single-child group reached an agreement than the other two groups. More than $60.0 \%$ of the couples said that the two-child policy was not influential on their decision to have a (further) child, with the highest proportion found among the childless couple group.

Table 1 Comparison of socioeconomic characteristics among couples with different family size

\begin{tabular}{|c|c|c|c|c|}
\hline \multirow[b]{2}{*}{ Characteristic } & \multicolumn{3}{|c|}{ Number of children (\%) } & \multirow[b]{2}{*}{ p-value } \\
\hline & $\begin{array}{l}\text { None } \\
(n=700)\end{array}$ & $\begin{array}{l}\text { One } \\
(n=842)\end{array}$ & $\begin{array}{l}\text { Multiple } \\
(n=471)\end{array}$ & \\
\hline Ethnicity & & & & $<0.001$ \\
\hline Han & $492(70.3)$ & $688(81.7)$ & $410(87.0)$ & \\
\hline Other & $208(29.7)$ & $154(19.3)$ & $61(13.0)$ & \\
\hline \multicolumn{5}{|l|}{ Education } \\
\hline Both senior high school or below & $243(34.7)$ & $425(50.5)$ & $381(80.9)$ & $<0.001$ \\
\hline At least one university degree or above & $457(65.3)$ & $417(49.5)$ & $90(19.1)$ & \\
\hline \multicolumn{5}{|l|}{ Employment status } \\
\hline Both self-employed & $191(27.3)$ & $336(39.9)$ & $356(75.6)$ & $<0.001$ \\
\hline At least one employed & $509(72.7)$ & $506(60.1)$ & $115(24.4)$ & \\
\hline Monthly income (yuan) & & & & $<0.001$ \\
\hline$\leq 3,000$ & $60(8.6)$ & $97(11.5)$ & $153(32.5)$ & \\
\hline $3,001-6,000$ & $240(34.3)$ & $302(35.9)$ & $168(35.7)$ & \\
\hline$>6,000$ & $400(57.1)$ & $443(52.6)$ & $150(31.8)$ & \\
\hline Women's marital age, median (IQR) & $27(25.0,28.0)$ & $26(24.0,27.0)$ & $24(22.0,26.0)$ & $<0.001^{\dagger}$ \\
\hline
\end{tabular}

Numbers are frequency (\%) unless specified

$\mathrm{p}$-values from the chi-square test unless indicated otherwise. ${ }^{\dagger} \mathrm{Kruskal}-\mathrm{Wallis}$ test

IQR=interquartile range 


\section{Multivariate log-binomial regression}

Table 3 shows the results of the multivariate logbinomial regression analysis comparing socio-demographic factors between childless couples and couples with one and more than one child. Significant differences were found in terms of socio-demographic characteristics, intercouple communication, and attitude towards the influence of the two-child policy on the number of children to raise. Increasing wife's age at marriage, higher education level, and higher income were significantly associated with a reduced prevalence of raising children. In contrast, lack of inter-couple agreement on the desired number of children to raise was significantly associated with a $17.0 \%$ increased prevalence of raising one child but not with raising multiple children. However, the perception that the two-child policy influences a couple's decision to raise children was significantly associated with an increase in the prevalence of raising one $(\mathrm{PR}=1.08,95 \% \mathrm{Cl}=1.04-$ 1.12) and multiple ( $P R=1.14,95 \% \mathrm{Cl}=1.09-1.19)$ children.

\section{Main reasons influencing a couple's decision} to raise a child

Among couples who were childless, the main motivation to have a child was the subjective norm of "a child is a bond of a couple" (47.6\%). The top reason among couples with a single child $(76.6 \%)$ and those with multiple children (74.9\%) was the subjective norm of "two children can keep each other company". The most important difficulty in raising a child stated by all three groups was the perceived behavior control of "raising a (further) child increases the economic burden" (Table 4).

Table 2 Attitude towards universal two-child policy and communication between couples about number of children

\begin{tabular}{|c|c|c|c|c|}
\hline \multirow{2}{*}{ Attitude } & \multicolumn{3}{|c|}{ Number of children (\%) } & \multirow{2}{*}{ p-value ${ }^{\dagger}$} \\
\hline & None & One & Multiple & \\
\hline Agreement on the number of children in family & & & & $<0.001$ \\
\hline Agree & $570(81.4)$ & $599(71.1)$ & $383(81.3)$ & \\
\hline Disagree or no discussion & $130(18.6)$ & $243(28.9)$ & $88(18.7)$ & \\
\hline Influence of the two-child policy on number of children & & & & $<0.001$ \\
\hline No & $476(68.0)$ & $549(65.2)$ & $269(57.1)$ & \\
\hline Yes & $224(32.0)$ & $293(34.8)$ & $202(42.9)$ & \\
\hline
\end{tabular}

${ }^{\dagger}$ Chi-square test

Table 3 Multivariate log-binomial regression analysis comparing socio-demographic factors between childless couples (baseline) with single- and multiple-child couples

\begin{tabular}{lll}
\hline Characeristic & $\begin{array}{l}\text { One child } \\
\text { Adjusted PR (95\% Cl) }\end{array}$ & $\begin{array}{l}\text { Multiple children } \\
\text { Adjusted PR (95\% Cl) }\end{array}$ \\
\hline $\begin{array}{l}\text { Wife's age at marriage (years) } \\
\text { Ethnicity }\end{array} \quad$ 0.98 $(0.97,0.98)$ & $0.97(0.97,0.98)$ \\
$\quad \begin{array}{l}\text { At least one minority } \\
\text { Both Han }\end{array}$ & Ref & Ref \\
\hline
\end{tabular}


Table 3 Multivariate log-binomial regression analysis comparing socio-demographic factors between childless couples (baseline) with single- and multiple-child couples

\begin{tabular}{|c|c|c|}
\hline Characeristic & $\begin{array}{l}\text { One child } \\
\text { Adjusted PR }(95 \% \mathrm{Cl})\end{array}$ & $\begin{array}{l}\text { Multiple children } \\
\text { Adjusted PR }(95 \% \mathrm{Cl})\end{array}$ \\
\hline \multicolumn{3}{|l|}{ Education } \\
\hline Both junior college and below & Ref & Ref \\
\hline At least one university & $0.70(0.66,0.74)$ & $0.38(0.35,0.43)$ \\
\hline \multicolumn{3}{|l|}{ Employment status } \\
\hline Both self-employed & Ref & Ref \\
\hline At least one employed & $1.00(0.95,1.05)$ & $0.72(0.65,0.79)$ \\
\hline \multicolumn{3}{|l|}{ Monthly income (yuan) } \\
\hline$\leq 3,000$ & Ref & Ref \\
\hline $3,001-6,000$ & $0.93(0.88,0.98)$ & $0.90(0.87,0.94)$ \\
\hline$\geq 6,000$ & $0.96(0.91,1.00)$ & $0.92(0.87,0.98)$ \\
\hline \multicolumn{3}{|c|}{ Agreement on the number of children } \\
\hline Agree & Ref & Ref \\
\hline Disagree or no discussion & $1.17(1.13,1.22)$ & $1.00(0.99,1.00)$ \\
\hline \multicolumn{3}{|c|}{ Influence of two child policy on decision to have a (further) child } \\
\hline No & Ref & Ref \\
\hline Yes & $1.08(1.04,1.12)$ & $1.14(1.09,1.19)$ \\
\hline
\end{tabular}

$\mathrm{PR}=$ prevalence ratio, $\mathrm{Cl}=$ confidence interval, Ref=reference group

Table 4 Ranking of main reasons for and difficulties against raising a child

\begin{tabular}{|c|c|c|c|c|}
\hline $\begin{array}{l}\text { Number } \\
\text { of children }\end{array}$ & Motivation to have children & $\%$ & Major difficulties in raising children & $\%$ \\
\hline \multirow[t]{3}{*}{ None } & A child is a bond of a couple & 47.6 & Increase in the economic burden & 63.4 \\
\hline & Fosters a good marital relationship & 43.9 & Lack of time & 53.0 \\
\hline & I like children & 40.1 & $\begin{array}{l}\text { Can negatively affect the chances of } \\
\text { promotion in the work place }\end{array}$ & 35.3 \\
\hline \multirow[t]{3}{*}{ One } & Two children can keep each other company & 76.6 & Increase in the economic burden & 71.5 \\
\hline & Children are the hope of the family & 34.7 & Lack of time & 62.1 \\
\hline & Enjoy having fun with child & 33.7 & $\begin{array}{l}\text { It is difficult to raise a (further) child in modern } \\
\text { society }\end{array}$ & 47.5 \\
\hline \multirow[t]{3}{*}{ Multiple } & Two children can keep each other company & 74.9 & Increase in the economic burden & 76.6 \\
\hline & Enjoy having fun with child & 39.5 & Lack of time & 58.2 \\
\hline & Children are the hope of the family & 37.8 & It is difficult to raise a child in modern society & 46.1 \\
\hline
\end{tabular}




\section{Discussion}

"Two children can keep each other company" was the major motivating reason given by single-child (76.6\%) and multi-child couples $(74.9 \%)$ in influencing their decision to raise another child. The first generation under the one-child policy has now entered the age of childbearing; they are the loneliest generation in China as few have blood brothers or sisters. ${ }^{23}$ A study found that Chinese college students, as an only child, reported higher levels of loneliness than their counterparts. ${ }^{24}$ These generation couples now have the opportunity to fulfill their wishes and prevent their offspring from experiencing the isolation they felt during their own childhood. However, the reality is that there are other difficulties preventing a couple to achieve their desires to have multiple children since the top barrier in raising children stated by couples in this study was the increased economic burden. At the end of 2014 , the proportion of elderly people living in Inner Mongolia reached $8.8 \%{ }^{20}$, which is a significant level because couples of childbearing age had to weigh two competing roles: provide care to their own parents and parents-in-law or raise their own children. One-third of Chinese middle-aged individuals are sandwiched between their older parents/parents-in-law and younger grandchildren; thus they now face the responsibility of providing informal care to both generations. ${ }^{25}$ The same social norm and traditional family structures also mean that many Chinese grandparents are expected to provide care for their young children. ${ }^{26}$ Thus, having a single child is a necessity, whereas having multiple children is a luxury for most couples.

Couples who had multiple children in this study were characterized by having a lower educational attainment $(80.9 \%)$, being self-employed (75.6\%), having a monthly income less than 6,000 yuan, and a wife whose age at marriage was younger (24 years) than the other two groups. These findings can be explained by the fact that couple's educational attainment, occupation, and income are inter-related. Individuals who invest more in education tend to marry more educated partners than those who don't. ${ }^{27}$ As commonly seen, increased education is associated with a reduction in completed fertility, which operates through a postponement of first birth in life. ${ }^{28}$ In addition, the strong association between higher educational attainment with decreased fertility outcome can be explained by the awareness of the duties and burdens of childrearing. ${ }^{29}$ Some researchers have confirmed that couple's workforce participation reduces their parental childcare time $^{30}$ and postponed childbirth ${ }^{31}$, which have the same impact on women and men. Finally, considering about having a child or not, each partner considers not only his or her own intention but also the resources and plans of their partner, thus, the relatively low socioeconomic characteristics have a greater impact on fertility outcome. ${ }^{32}$

From this study, Han couples were more likely to have one child compared with couples belonging to an ethnic minority group, and couples with one or multiple children were more likely to perceive the influence of the two-child policy compared with childless couples. Since 1984, the one-child policy has changed from a strictly unified to decentralized autonomy implementation, which was executed by the local family regulations. ${ }^{33}$ Couples in some rural areas, autonomous regions, and minority inhabited districts were allowed to have a second child. ${ }^{34}$ Han, who mainly live in urban areas, were the main group that was constrained by the previous one-child policy. The impact of the "policy inertia" was significant among couples in our study who were both Han. Evidence from a national survey suggested that China has become a small-family culture; couples are younger, more urbanized, educated, and have fewer children. ${ }^{35}$ The fertility rate in Inner Mongolia, and perhaps the whole country, may not increase as expected in the short-term, as some researchers believe that the economic conditions of the 
family, rather than the population policy, is the main driving force for most Chinese families towards the fertility outcome. ${ }^{4}$ However, China's two-child policy will still have a substantial effect on the population size, fertility rate, age structure, sex ratio, and health systems in the long-term. .2,36,37 $^{2}$

There are some limitations in this study which need mentioning. First, since the study setting was Inner Mongolia, the results of this study cannot be generalized to the whole country. Second, the cross-sectional design limits making causal inferences of a couple's socioeconomic characteristics on the number of children they have. In addition, we could not obtain all socio-demographic details of those who refused to participate in order to check whether they differed from the participating subjects or not. However, with a $10.0 \%$ refusal rate, the study results would not have changed very much had they been included. With better access to panel data and national household surveys, these limitations can be addressed.

\section{Conclusion}

Increased economic burden was the top difficulty for raising children stated by all couples, regardless of whether or not they already had a child. A negative association was found between family size and a couple's socioeconomic characteristics, which included wife's marital age, and a couple's educational level and monthly income. Both single-child and multi-child couples were more influenced by the two-child policy than childless couples. Han couples, who mainly live in urban areas, were constrained by the previous one-child policy, and those who could not agree on the number of children to have were more likely to have a single child. The results of this study should give more insight into the expectations of couples who plan to have a (further) child and this should help the Chinese government improve the infrastructure and social welfare system of the whole society.

\section{Acknowledgement}

This study is a part of the first author's thesis in partial fulfillment of the requirements for a Ph.D. at Prince of Songkla University, Thailand and the China Medical Board under the project of "A second collaborative program to improve the health research capacity of western medical universities in China and Prince of Songkla University. We thank the Research Institute for Health Policy of Inner Mongolia, Inner Mongolia Medical University. The authors would also like to thank all participants who enrolled in this study.

\section{Funding sources}

This research was funded by the Key Research Based of Humanities and Social Science of Inner Mongolia Autonomous Region of China, China Medical Board, and Prince of Songkla University.

\section{Conflict of interest}

The authors declare that they have no competing interests.

\section{References}

1. Lacovou M, Tavares LP. Yearning, learning, and conceding: reasons men and women change their childbearing Intentions. Popul Dev Rev 2011;37:89-123.

2. Chen M, Yip PS. The discrepancy between ideal and actual parity in Hong Kong: fertility desire, intention, and behavior. Popul Res Policy Rev 2017;36:583-605.

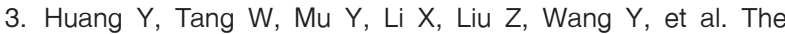
sex ratio at birth for $5,338,853$ deliveries in China from 2012 to 2015: a facility-based study. PloS One 2016;11. doi: 10.1371/journal.pone.0167575.

4. Qin M. Evolution of family planning policy and its impact on population change in China. Southampton: University of Southampton; 2016.

5. Jones GW. Ultra-low fertility in East Asia: policy responses and challenges. Asian Popul Stud 2019;15:131-49. 
6. Son YJ. Do childbirth grants increase the fertility rate? Policy impacts in South Korea. Rev Econ Househ 2018;16: 713-35.

7. Nagase N. The effect of family-friendly policies on fertility and maternal labor supply. California: Stanford University; 2017.

8. Swee-Hock S. Population policies and programmes in Singapore. Hawaii: ISEAS-Yusof Ishak Institute; 2016.

9. Liu F, Bao J, Boutain D, Straughn M, Adeniran O, DeGrande $\mathrm{H}$, et al. Online responses to the ending of the one-child policy in China: implications for preconception care. Ups $J$ Med Sci 2016:1-8.

10. Schwank SE, Gu C, Cao Z, Andersson E, Jiang H, Ding Y, et al. China's child policy shift and its impact on Shanghai and Hangzhou women's decision-making. Int J Womens Stud 2018;10:639.

11. Bollen KA, Glanville JL, Stecklov G. Socio-economic status, permanent income, and fertility: a latent-variable approach. Popul Stud 2007;61:15-34.

12. Monstad K, Propper C, Salvanes KG. Education and fertility: evidence from a natural experiment. Scand J Econ 2008;110: 827-52.

13. Begall K, Mills MC. The influence of educational field, occupation, and occupational sex segregation on fertility in the Netherlands. Eur Sociol Rev 2012;29:720-42.

14. Lan M, Kuang Y. The impact of women's education, workforce experience, and the one child policy on fertility in China: a census study in Guangdong, China. Springer Plus 2016;5:1708.

15. Bao L, Chen F, Zheng Z. Transition in second birth intention in a low fertility context: the case of Jiangsu, China. Asian Popul Stud 2017;13:198-222.

16. Jiang $Q$, Li $Y$, Sanchez-Barricarte JJ. Fertility intention, son Preference, and second childbirth: survey findings from Shaanxi province of China. Soc Indic Res 2016;125:935-53.

17. Breierova L, Duflo $E$. The impact of education on fertility and child mortality: do fathers really matter less than mothers? Cambridge: National bureau of economic research; 2004.

18. Press CS. Basic satistics on all region population census in 1953, 1964, 1982, 1990, 2000 and 2010 [monograph on the Internet]. Inner Mongolia Autonomous Regional: China Statistics Press; 2018 [cited 2019 Dec 20]. Available from: http://tj.nmg.gov.cn/Files/tjnj/2018/zk/indexeh.htm
19. Keyong D. Population aging and its influences on the economy and society in China. Beijing: Renmin University of China; 2016.

20. Press CS. Characteristic of aging problem in inner mongolia [monograph on the Internet]. Inner Mongolia: Inner Mongolia of China Statistics Press; 2015 [cited 2019 Dec 15]. Available from: http://www.nmgtj.gov.cn/nmgttj/tjfx/webinfo/2016/01/ 1441781739054285.htmInner

21. Rich A, Brandes K, Mullan B, Hagger MS. Theory of planned behavior and adherence in chronic illness: a meta-analysis. J Behav Med 2015;38:673-88.

22. Zeng $Y$, Hesketh T. The effects of China's Universal twochild policy. Lancet 2016;388:1930-8.

23. Zhang N, Fan Fm, Huang Sy, Rodriguez MA. Mindfulness training for loneliness among Chinese college students: a pilot randomized controlled trial. Int J Psychol 2018;53: 373-8.

24. Hawkley LC, Gu Y, Luo YJ, Cacioppo JT. The mental representation of social connections: generalizability extended to Beijing adults. PloS One 2012;7. doi: 10.1371/journal.pone. 0044065.

25. Falkingham J, Evandrou M, Qin M, Vlachantoni A. Informal care provision across multiple generations in China. Southampton: University of Southampton; 2019.

26. Chen F, Liu G, Mair CA. Intergenerational ties in context: grandparents caring for grandchildren in China. Social Forces 2011;90:571-94.

27. Anderberg $D$, Zhu $Y$. What a difference a term makes: the effect of educational attainment on marital outcomes in the UK. J Popul Econ 2014;27:387-419.

28. Cygan-Rehm K, Maeder M. The effect of education on fertility: evidence from a compulsory schooling reform. Labour Econ 2013;25:35-48.

29. Nozaki $Y$. The effects of higher education on childrearing fertility behavior in Japan. Int J Soc 2017;44:653-69.

30. Molina JA, Montuenga VM. The motherhood wage penalty in Spain. J Fam Econ Issues 2009;30:237-51.

31. Billingsley S, Puur A, Sakkeus L. Jobs, careers, and becoming a parent under state socialist and market conditions: evidence from Estonia 1971-2006. Demographic Res 2014;30:1733-68.

32. Osiewalska B. Childlessness and fertility by couples' educational gender (in) equality in Austria, Bulgaria, and France. Demographic Res 2017;37:325-62. 
33. Wang C. History of the Chinese family planning program: 19702010. Contraception 2012;85:563-9.

34. Zhang Y. A qualitative study of Chinese women's fertility desire in light of the recent two-child policy. Scania: Lund University; 2018.

35. Hesketh T, Lu L, Xing ZW. The effect of china's one-child family policy after 25 years. N Engl J Med 2005;353:1171-6.
36. Yi Zeng ZW. A policy analysis on challenges and opportunities of population/household aging in China. Popul Ageing 2014;7:255-81.

37. Huang J, Qin D, Jiang T, Wang Y, Feng Z, Zhai J, et al. Effect of fertility policy changes on the population structure and economy of China: from the perspective of the shared socioeconomic pathways. Washington: AGU-100; 2019. 